\title{
Effect of Different Parameters on Mechanical and Erosion Wear Behavior of Bamboo Fiber Reinforced Epoxy Composites
}

\author{
Anu Gupta, ${ }^{1}$ Ajit Kumar, ${ }^{1}$ Amar Patnaik, ${ }^{2}$ and Sandhyarani Biswas ${ }^{3}$ \\ ${ }^{1}$ School of Engineering and Technology, IGNOU, New Delhi 110068, India \\ ${ }^{2}$ Department of Mechanical Engineering, N I T, Hamirpur 177005, India \\ ${ }^{3}$ Department of Mechanical Engineering, N I T, Orissa, Rourkela 769008, India
}

Correspondence should be addressed to Amar Patnaik, amar_mech@sify.com

Received 30 March 2011; Revised 15 May 2011; Accepted 14 June 2011

Academic Editor: Bibin Mathew Cherian

Copyright (C) 2011 Anu Gupta et al. This is an open access article distributed under the Creative Commons Attribution License, which permits unrestricted use, distribution, and reproduction in any medium, provided the original work is properly cited.

\begin{abstract}
The application of natural fibers as reinforcement in polymer composites has been continuously growing during the last few decades. These composites find diverse applications in hostile environment where they are exposed to external attacks such as solid particle erosion. Also, in many respects, the mechanical properties of different polymer composites are their most important characteristics. Therefore, improvement of the erosion resistance and mechanical behavior of polymer composites are the prime requirements in their applications. Bamboo fiber which is rich in cellulose, relatively inexpensive, and abundantly available has the potential for reinforcement in polymers. To this end, an attempt has been made in this paper not only to study the utilization potential of bamboo fiber in polymer composites but also to study the effect of various parameters on mechanical and erosion wear performance of bamboo fiber reinforced epoxy composites.
\end{abstract}

\section{Introduction}

Fiber-reinforced polymers are increasingly becoming potential candidates for replacing conventional materials due to their many advantages. These composites are finding applications in diverse fields starting from appliances to spacecrafts. The application of natural fibers as reinforcement in polymer composites has been continuously growing during the last few years. The main advantages of such fibers are their low cost, renewability, biodegradability, low specific gravity, abundance, high specific strength, and stiffness. Among the various natural fibers, bamboo finds widespread use in housing construction around the world and is considered as a promising construction material for housing applications in both developed and underdeveloped countries. Being a conventional construction material since ancient times, bamboo fiber is a good candidate for use as natural fibers in composite materials. The reason that many studies focus on bamboo is because bamboo is an abundant natural resource in Asia, and its overall mechanical properties are comparable to those of other related wood composites. Furthermore, bamboo can be renewed much more rapidly compared with wood. Bamboo is an extremely light weight, functionally graded, and high strength natural composite. Polymer composites find various applications in hostile environment where they are subjected to external attacks such as solid particle erosion. In many respects, the mechanical properties of different polymer composites are their most important characteristics. Therefore, improvement of the erosion resistance and mechanical behavior of polymer composites are the prime requirements in their applications.

The properties of polymer composites are greatly influenced by many factors. The effect of fiber loading, fiber length, fiber and orientation has significant influence on mechanical behavior of polymer composites and is studied by many investigators [1-4]. Also, the influence of parameters such as concentration, impact velocity, impingement angle, fiber geometry, and shapes of the particles on erosion rate is very significant, and any changes in them can considerably affect the rate of material loss [5]. The erosive wear behavior of polymer composite systems as a function of fiber $[6,7]$, particle $[8,9]$ and fabric content $[10,11]$, fiber and filler type $[6,12]$, fiber orientation $[7,13,14]$, fiber length $[7,15]$, impingement angle $[6-8,12-14,16]$, 


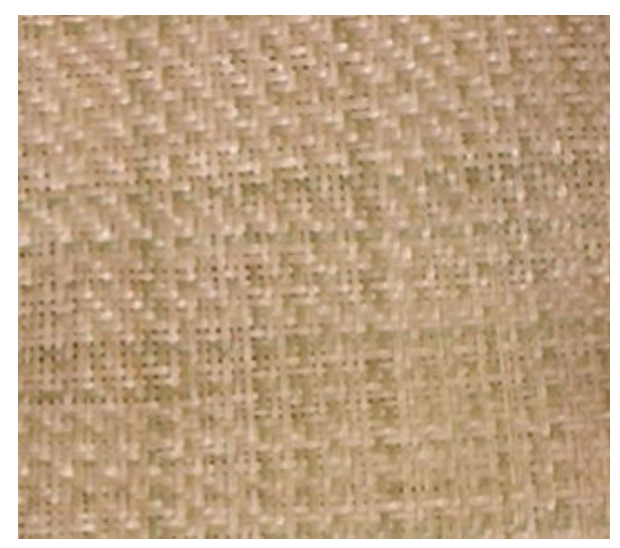

FIgURE 1: Bidirectional roving bamboo fiber.

impact velocity $[8,13]$, and erodent mass direction [16] has been studied previously. Although a great deal of work has been made on effect of various parameters on mechanical and wear behavior of different class of polymer composites, research on effect of parameters on natural-fiber-based polymer composites is rare. To this end, in the present research work, an attempt has been made to study the effect of various parameters on mechanical and erosion wear behavior of bamboo fiber reinforced epoxy composites.

\section{Experimental Details}

2.1. Composite Fabrication. Bidirectional bamboo fibers are collected from local sources. Epoxy LY 556 and the corresponding hardener (HY951) are supplied by Ciba Geigy India Ltd. In general, bamboo culm is a thin-walled hollow cylinder separated with nodes. In the present study, three straight internodes, $250-300 \mathrm{~mm}$ in length and $150 \mathrm{~mm}$ in diameter, obtained from the midheight of 3-year-old bamboo are used. These "tubes" are then divided into rods of average diameter $2.5 \mathrm{~mm}$ and length of $150 \mathrm{~mm}$. These rods are then separated into several types of strips depend on individual requirements. The extracted fibers are dried in an oven at $45^{\circ} \mathrm{C}$ for $4 \mathrm{~h}$ to remove moisture. Each ply of roving bidirectional bamboo mat (Figure 1) is of dimension $150 \times$ $150 \mathrm{~mm}^{2}$. The average diameter of bamboo fibers is about $2.5 \mathrm{~mm}$. Composites slabs are made by reinforcing bamboo mats in epoxy resin using simple hand lay-up technique followed by light compression molding, as hand lay-up technique is a simple method for composite production. A mold must be used for hand-lay-up parts unless the composite is to be joined directly to another structure. The mold can be as simple as a flat rectangular sheet. For some shapes, molds must be joined in sections, so they can be taken apart for part removal after curing. Before layup, the mold is prepared with a release agent to insure that the part will not adhere to the mold. Reinforcement fibers can be cut and laid in the mold. It is up to the designer to organize the type, amount, and direction of the fibers being used. Resin must then be catalyzed and added to the fibers. A brush, roller or squeegee can be used to impregnate the
TABLE 1: Test parameters.

\begin{tabular}{ll}
\hline Erodent & Silica sand \\
\hline Erodent size $(\mu \mathrm{m})$ & $125-300$ \\
Erodent shape & Irregular, square pyramidal \\
Impingement angle $(\alpha, \circ)$ & $15,30,60,90$ \\
Impact velocity $(\mathrm{m} / \mathrm{s})$ & $30 \pm 4,52 \pm 4,60 \pm 4,88 \pm 4$ \\
Erodent feed rate $(\mathrm{g} / \mathrm{min})$ & $4.7 \pm 0.3$ \\
Test temperature & $\mathrm{RT}$ \\
Nozzle to sample distance $(\mathrm{mm})$ & 10 \\
Nozzle diameter $(\mathrm{mm})$ & 4 \\
\hline
\end{tabular}

fibers with the resin. The lay-up technician is responsible for controlling the amount of resin and the quality of saturation. The castings are put under load for about $24 \mathrm{~h}$ for proper curing at room temperature. The composites of five different compositions ( $0 \mathrm{wt} \%, 10 \mathrm{wt} \%, 20 \mathrm{wt} \%, 30 \mathrm{wt} \%$, and $40 \mathrm{wt} \%$ fiber loading) are made. After the curing process, test samples are cut to the required sizes as per individual test requirements.

2.2. Physical and Mechanical Properties. The theoretical density of composite materials is obtained as per the equation given by Agarwal and Broutman [17]. The actual experimental density of the composites is determined by simple water immersion technique, and finally the volume fractions of the composites are calculated. Tensile testing of the composites specimen is carried out using an Instron universal testing machine, Model 1195, at a crosshead speed of $10 \mathrm{~mm} \mathrm{~min}^{-1}$. Rectangular specimens of size $150 \times 10 \times$ $3 \mathrm{~mm}^{3}$ were used for testing. Flexural tests (three-point bend test) were conducted on all the composite samples in the universal testing machine Instron 1195. The dimension of each specimen is $60 \mathrm{~mm} \times 10 \mathrm{~mm} \times 4 \mathrm{~mm}$. Span length of $40 \mathrm{~mm}$ and the cross-head speed of $10 \mathrm{~mm} / \mathrm{min}$ are maintained. Charpy impact tests on specimens were performed using a pendulum impact testing machine. The standard specimen size as per ASTM D 256 is $64 \mathrm{~mm} \times 12.7 \mathrm{~mm} \times 3.2 \mathrm{~mm}$ and the depth under the notch is $10 \mathrm{~mm}$. For evaluation of tensile, flexural, and impact properties, five specimens were tested and average values are reported.

2.3. Erosion Test. The set up for the solid particle erosion wear test (as per ASTM G76) used in this study is capable of creating reproducible erosive situations for assessing erosion wear resistance of the prepared composite samples. The erosion test rig is used for erosion testing of composite samples with the different test parameters given in Table 1. The solid particle erosion test rig consists of a compressor, drying unit, a conveyor belt-type particle feeder which helps to control the flow of sand particle, and an air-particle mixing and accelerating chamber. The compressed air is then mixed with the selected range of silica sand which is fed constantly by a conveyor belt feeder into the mixing chamber and then passing the mixture through a convergent brass nozzle of internal diameter of $3 \mathrm{~mm}$. 


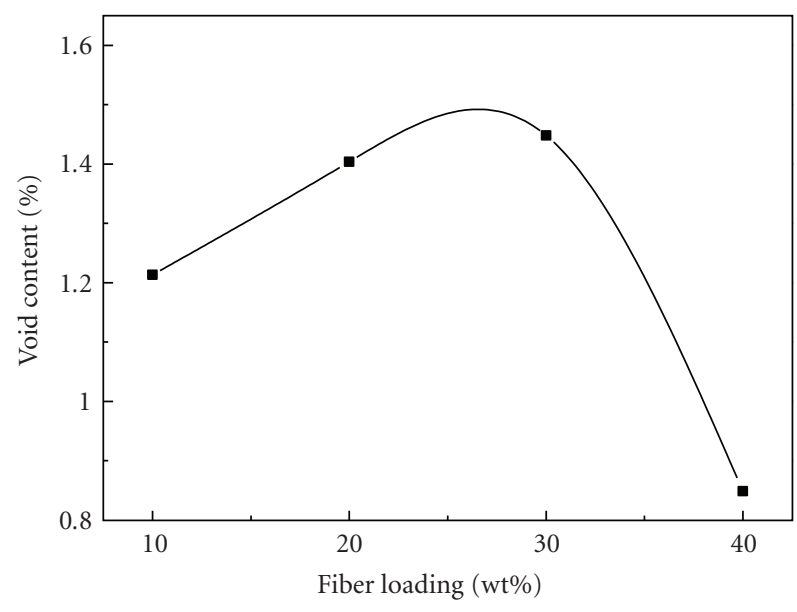

FIGURE 2: Effect of fiber loading on void content of composites.

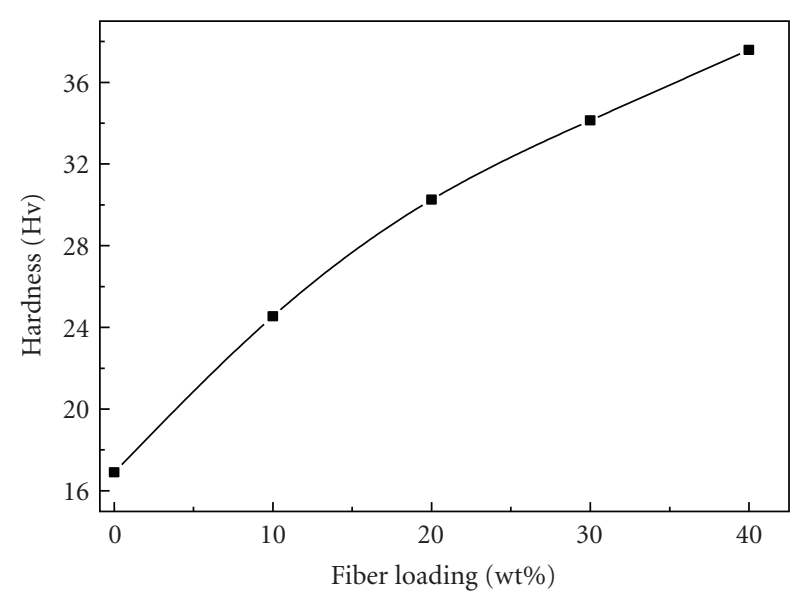

FIgURE 3: Effect of fiber loading on hardness of composites.

The erodent particles impact the specimen which can be held at different angles with respect to the direction of erodent flow using a swivel and an adjustable sample holder. The velocity of the eroding particles is determined using standard double disc method [18]. In the present study, pyramidal-shaped dry-silica sand of different particle sizes are used as erodent. After each experimental run, the eroded samples are cleaned in acetone and dried for 5 minutes and then weighed to an accuracy of $\pm 0.01 \mathrm{mg}$ using an electronic balance. The weight loss is recorded for subsequent calculation of erosion rate. The process is repeated till the erosion rate attains a constant value called steady state erosion rate.

2.4. Scanning Electron Microscopy (SEM). The surfaces of the specimens are examined directly by scanning electron microscope (SEM) JEOL JSM-6480LV. The eroded samples are mounted on stubs with silver past. To enhance the conductivity of the eroded samples, a thin film of platinum is vacuum evaporated onto them before the photomicrographs are taken.

\section{Results and Discussion}

3.1. Effect of Fiber Loading on Physical and Mechanical Properties of Composites. The density is a material property which is of prime importance in several weight sensitive applications. There is always a difference between the theoretical and the measured density values of a composite due to the presence of voids and pores. It is well documented that presence of voids is one of the main factors influencing the mechanical performance of composites and the knowledge of void content is desirable for estimation of the quality of the composites. Porosity is identified as air-filled cavities formed inside the composites, and is often an unavoidable part in all composites. The void may be developed during the mixing and consolidation of two or more different material parts. Månson et al. [19] studied different processing and manufacturing techniques for synthetic fiber composites and considerable knowledge has been accumulated from the study to diminish the porosity part (i.e., to volume fractions below 0.01 ). In contrast, porosity in plant-fiber-reinforced composites makes usually a noteworthy contribution to the overall composite volume (i.e. weight fractions up to $40 \mathrm{wt} \%$ ) (Figure 2). Larger porosity content in plant fiberreinforced composites may be caused by a number of factors: (i) the existence of luminal cavities in plant fibers [20], (ii) the complex surface chemistry of plant fibers which complicates fiber/matrix compatibilization, (iii) the heterogeneous form and dimensions of plant fibers which restrict matrix impregnation $[21,22]$, and (iv) the low packing ability of plant fiber assemblies which limits the maximum obtainable fiber volume fraction [23]. Figure 2 shows the effect of fiber loading on void content of composites. From the figure, it is clearly observed that with the increase in fiber weight fraction the void content of the composites increases. However, on further increase in fiber loading ( $>30 \mathrm{wt} \%)$, the void content of the composite continuously decreases, and there may be perfect combination of fiber weight fraction and the matrix material. Hence, based up on the above analysis, it is clearly demonstrated that with increase in fiber loading the void content of the composites goes on decreasing.

Surface hardness of the composites is considered as one of the most important factors that govern the erosion resistance. The test results show that with the increase in fiber loading, the hardness (Hv) value of the bamboo-epoxy composites is improved (Figure 3). Oksman [24] reported clearly that inclusion of bamboo fiber in the epoxy matrix body results in improving the hardness of the composites although this improvement is marginal. This is because hardness is a function of the relative fiber volume and modulus [25].

With increasing wt $\%$ of bamboo fiber, the tensile strength of bamboo-epoxy composites decreases, as would be expected. Generally the tensile strength depends on the weakest part of the composites, and, may be, the interfacial interaction between epoxy and bamboo fiber is weak. Therefore, the tensile strength of the bamboo-epoxy composites decreases with increasing $\mathrm{wt} \%$ of bamboo fibers. Mwaikambo and Bisanda reported that, for polyester/cotton fabric composites, the tensile strength of the composites 


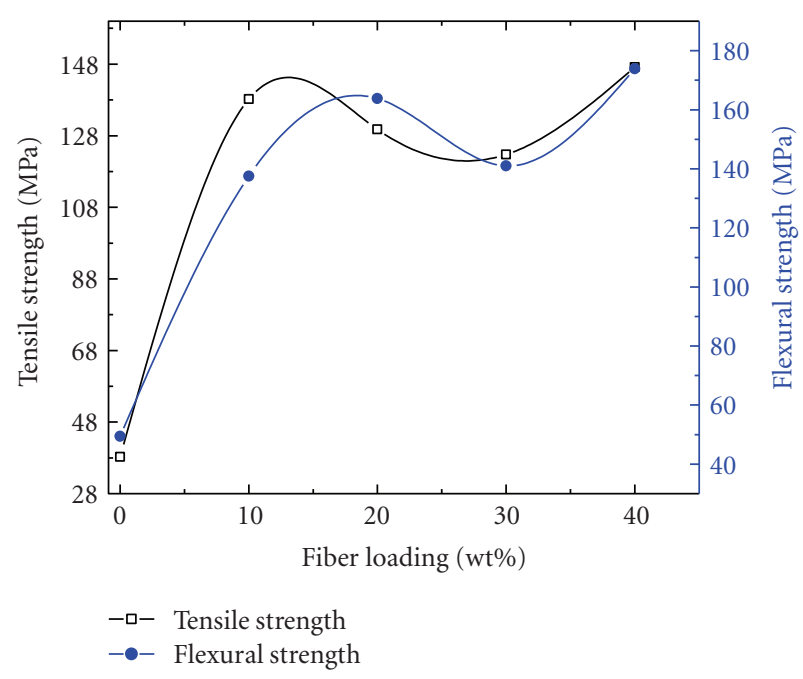

FIgURE 4: Effect of fiber loading on strength of composites.

decreased with increasing content of the cotton fabric, possibly because the void content increases with increasing fabric volume fraction [26]. However, in case of neat epoxy resin, the load increases linearly with displacement. Compared to other types of bamboo fiber composites, both peak load and displacement at failure of neat epoxy resin $(0 \mathrm{wt} \%$ of fiber loading) are the lowest. Such behaviour generally characterizes the brittleness nature of neat epoxy resin. This is the common observation for thermosetting polyester resin $[27,28]$.

Similar observation is also observed in the present research work as shown in Figure 4. With the increasing in fiber loading, the void content increases as reported in Figure 2. However, at $40 \mathrm{wt} \%$ of bamboo fiber reinforced epoxy composites, the void content decreases. Similarly, the tensile strength decreases with increasing in fiber loading. However, at $40 \mathrm{wt} \%$, fiber loading tensile strength of composite increases mostly due to less void content (Figure 2). The difference in the tensile strength depending on the kind of fiber can also be caused by other factors, such as the fiber length and hydrophilicity, as well as the difference in the chemical nature of the fiber.

The influence of fiber loading on flexural strength of bamboo-epoxy composite is also studied which also shows a similar observation, but a slight deviation is observed at $20 \mathrm{wt} \%$ fiber loading as shown in Figure 4. For the composites with $20 \mathrm{wt} \%$ of fiber loading, the flexural strength of the composites increases, and, with increasing fiber loading up to $30 \mathrm{wt} \%$, it decreases drastically. However, on further increase of fiber loading up to $40 \mathrm{wt} \%$, the composite shows maximum flexural strength. This behavior is similar to that of the tensile strength of composite except fiber loading of $10 \mathrm{wt} \%$. Adversely, as shown in Figure 4, the flexural strength increased by the increase of fiber loading up to $20 \mathrm{wt} \%$ fiber loading. For instance, flexural strength of bamboo-epoxy composite is increased from $137.5 \mathrm{MPa}$ to $163.8 \mathrm{MPa}$ and then decreased from $163.8 \mathrm{MPa}$ to $140.9 \mathrm{MPa}$, that is, up to

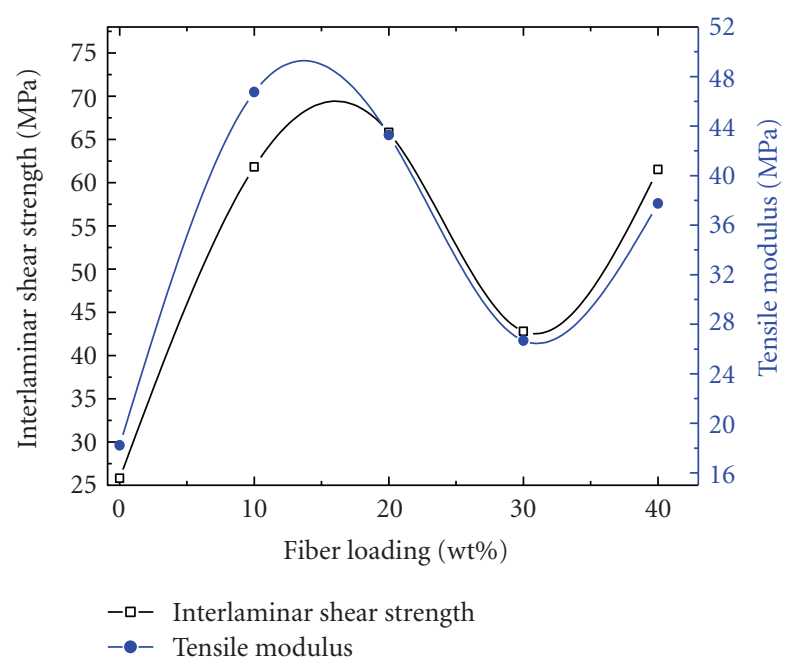

FIGURE 5: Effect of fiber loading on interlaminar shear strength and tensile modulus of composites.

$30 \mathrm{wt} \%$, but on further increase in fiber loading the flexural strength increases from 140.9 MPa to 173.8 MPa.

According to Ismail et al. [29] and Yao and Li [30], this decrease is attributed to the inability of the fiber to support stresses transferred from the polymer matrix and poor interfacial bonding generates partially spaces between fiber and matrix material which generates a weak structure. For a composite to be used in structural application, it must possess higher flexural strength because it is one of the important mechanical properties of the composites.

Short-beam shear strength is applied to the laminated bamboo epoxy composites to determine the interlaminar shear strength (ILSS) of composites fabricated with different fiber loading. With the addition of fiber loading from $0 \mathrm{wt} \%$ to $10 \mathrm{wt} \%$, the ILSS of laminates increases slightly, and, further increase in fiber loading up to $30 \mathrm{wt} \%$, the ILSS starts decreasing drastically, but again with the increase in fiber loading up to $40 \mathrm{wt} \%$, it shows quite different behaviour as shown in Figure 5.

The reduction may be related with the formation of voids in the matrix which is generally located at the interlaminar region of composites (Figure 2). The tendency of void formation is higher in $30 \mathrm{wt} \%$ fiber loading composite (void content: $1.448 \%$ ) as compared to $10 \mathrm{wt} \%$ bamboo fiber composite (void content: $1.213 \%$ ). This variation in property may be due to that the shear stress distribution is not parabolic and analysis is thus more complex than the conventional strength of materials analysis. The failure mode is strongly dependent on the ratio between length to support thickness, and the standard test methods suggest different ratios according to the type of material tested [31]. Similar observation is also reported in case of tensile strength as shown in Figure 5. The improvement in mechanical properties is due to the improvement in shear strength of the fiber/matrix interface bonding and also simultaneously may be an improvement in the macroscopic properties of the composite. However, the decrease in mechanical properties 


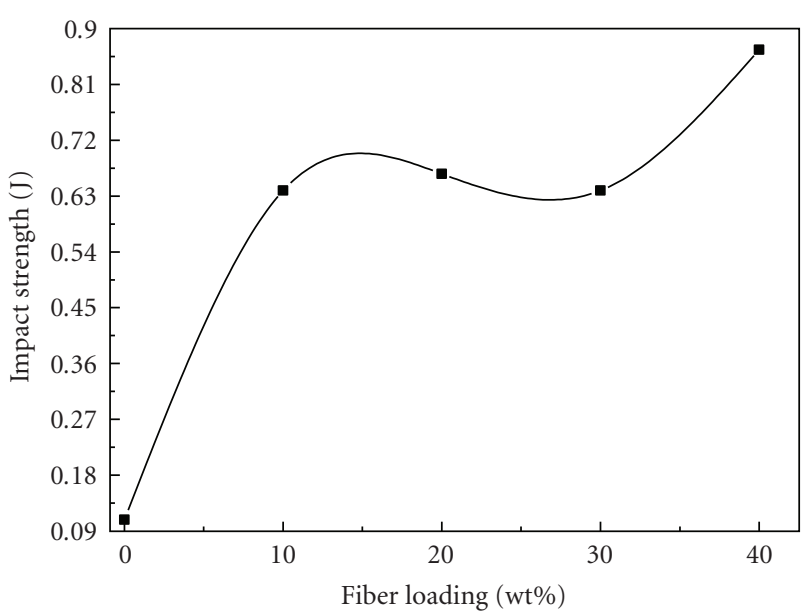

FIGURE 6: Effect of fiber loading on impact strength of composites.

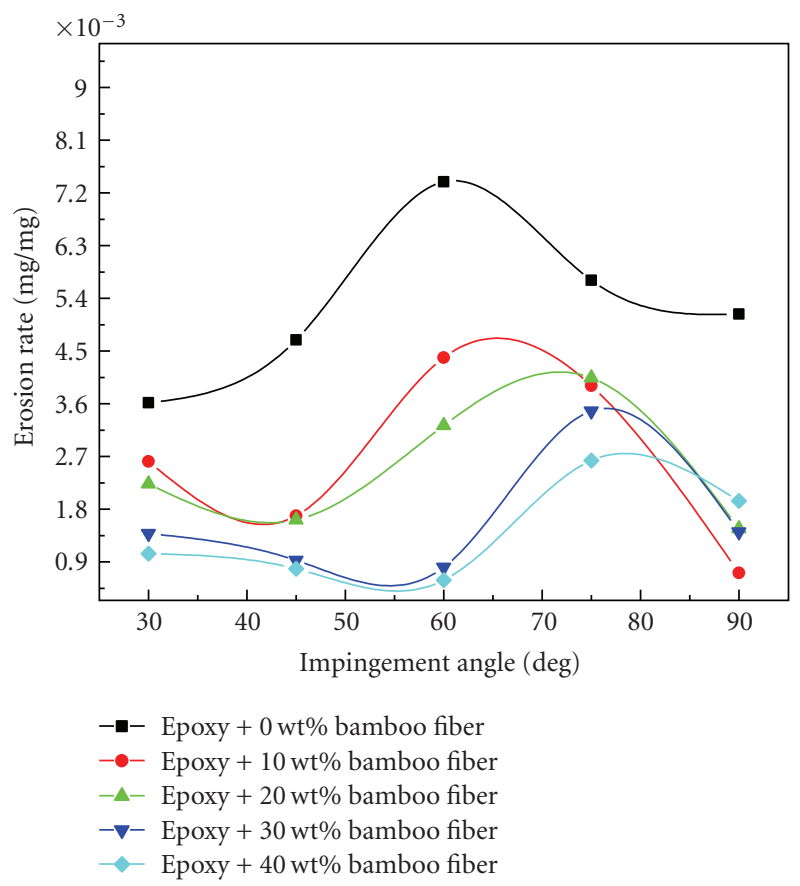

FIgURE 7: Effect of impingement angle on the erosion wear rate of the composites.

of any composites can be due to the poor interaction between matrix and fibers, which would make the fibers as the site of stress concentration. It induces microspaces between the fiber and matrix polymer, and as a result causes numerous microcracks when impact occurs, which induce crack propagation easily and decrease the impact strength of the composites $[32,33]$. This result proves that kenaf has higher properties [34] and can be less weakening agent than rice husk [35].

The impact strength of these composite materials is measured, and the results are reported in Figure 6. In this case, the impact strength increases linearly with increasing fiber loading from $0 \mathrm{wt} \%$ to $20 \mathrm{wt} \%$ (i.e., from $0.639 \mathrm{~J}$ to $0.666 \mathrm{~J})$ and then decreases nominal amount of energy $(0.639 \mathrm{~J})$, but, on further increase in fiber loading, the impact strength increases gradually with the increase in impact strength $(0.866 \mathrm{~J})$ as shown in Figure 6.

3.2. Effect of Impingement Angle on Erosion Rate. Erosion wear involves several wear mechanisms which are largely controlled by various parameters such as the angle of impingement, impact velocity, and particle size, particle material.

The angle of impingement is the angle between the eroded surface and the trajectory of the particle immediately before impact. In cases when erosion shows a maximum at low impingement angles, it is concluded that the "ductile mode of erosion wear" prevails $[36,37]$. Conversely, if the maximum erosion rate is found at high impingement angles, then the "brittle mode" is assumed [36, 37]. The effect of impingement angle on erosion rate of bamboo-epoxy composite is studied, and results are shown in Figure 7. It is evident from the figure that impingement angle has significant influence on erosion rate and the maximum erosion is occurring at an impingement angle of $60^{\circ}-75^{\circ}$ for all composite samples irrespective of fiber loading. So the mode of wear is neither a ductile erosion mode nor brittle erosion wear mode, it is behaving like semiductile/semibrittle mode of erosion wear.

3.3. Surface Morphology. The SEM observations explain to the results presented in the Figure 7 for bamboo fiber reinforced epoxy composites under steady state erosion rate studied at constant impact velocity $45 \mathrm{~m} / \mathrm{sec}$, erodent size $250 \mu \mathrm{m}$, and stand-off distance of $65 \mathrm{~mm}$ at controlled conditions with variations of impingement angle $\left(30\right.$ to $\left.90^{\circ}\right)$. Figure 8 shows the SEM of surfaces of the bamboo-epoxy composite eroded under various test conditions. Figures $8(\mathrm{a})$ and $8(\mathrm{~b})$ show the bamboo-epoxy composites with $10 \mathrm{wt} \%$ fiber loading which appears that composites under consideration exhibit several stages of erosion and material removal process. Very small craters and short cracks are seen on the eroded surface of the composite (Figure 7) at $30^{\circ}$ impingement angle. Increase in impingement angle to $45^{\circ}$ under similar operating conditions shows slight increase in erosion rate as evident from Figure 7 to $20 \mathrm{wt} \%$ fiber loading. This indicated that the initiation of matrix material loss from the surface and the matrix is chipped off and the bamboo fibers are slightly visible beneath the matrix layer after the impact of dry silica sand particles as shown in Figures $8(\mathrm{c})$ and $8(\mathrm{~d})$. But as the erosion tests are carried out with further higher impingement angle $\left(60^{\circ}\right)$ at constant impact velocity $45 \mathrm{~m} / \mathrm{sec}$, erodent size $250 \mu \mathrm{m}$, and standoff distance $65 \mathrm{~mm}$, the morphology of the eroded surface becomes different as in Figure 8(e) (Figure 7).

Such cracks are clearly noticed in Figure $8(\mathrm{e})$ and distinctly illustrate a crater formed due to material loss and the arrays of broken/semibroken bamboo fibers. Due to repeated impact of hard silica sand and higher impingement angle, the sand particles try to initiate cracks on the matrix body, and as erosion progresses gradually, these cracks 


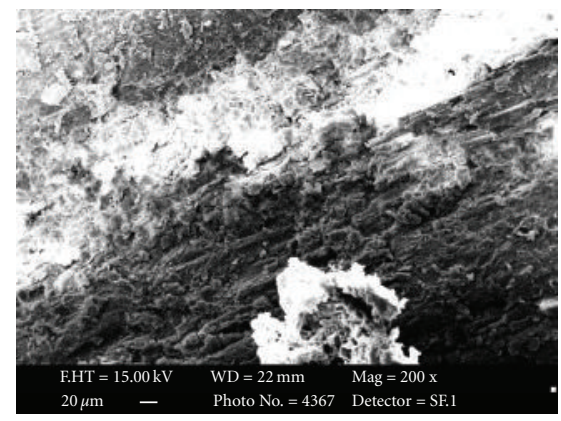

(a)

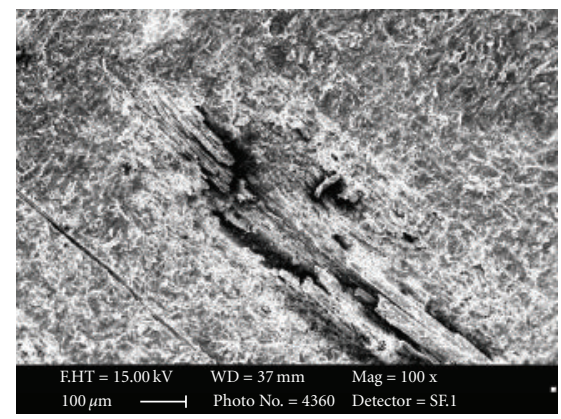

(d)

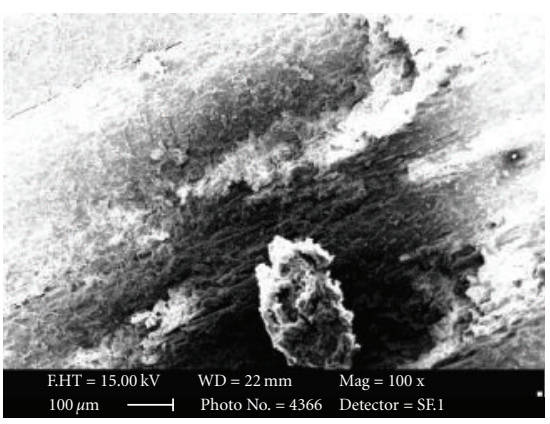

(b)

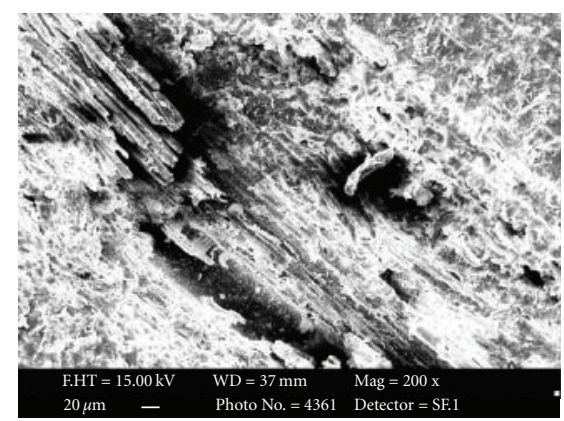

(e)

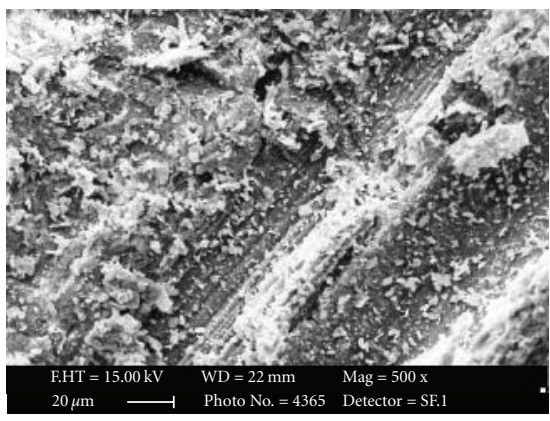

(c)

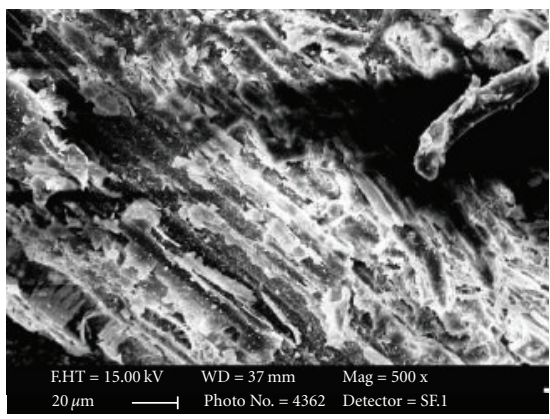

(f)

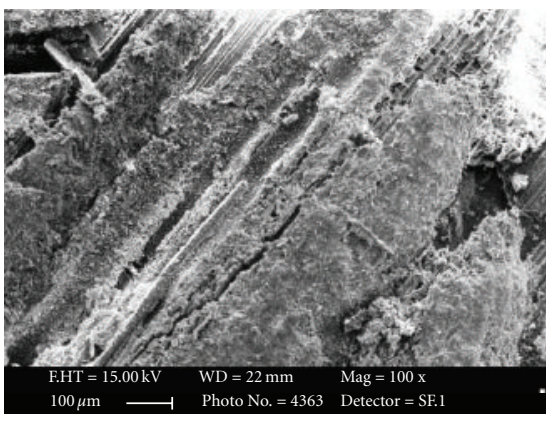

(g)

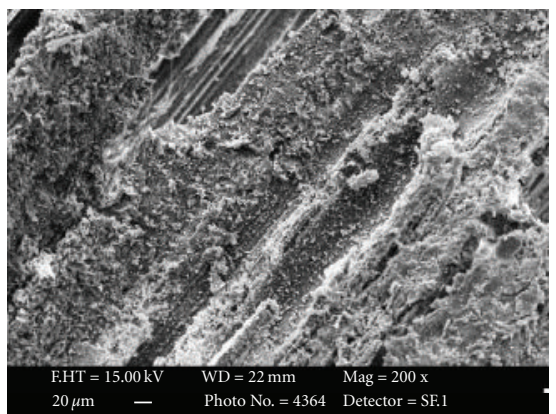

(h)

FIGURE 8: SEM observations of eroded samples with the variations of impingement angle.

subsequently propagate on the fiber bodies both in transverse as well as in longitudinal manner. But on further increase in impingement angle from $60^{\circ}$ to $75^{\circ}$, almost all the composites showed maximum erosion rate (Figure 7) as shown in Figure $8(\mathrm{f})$ for $30 \mathrm{wt} \%$ fiber loading. However, the SEM micrograph in Figures $8(\mathrm{~g})$ and $8(\mathrm{~h})$ shows less cracks or craters on the composite surface after erosion at an impingement angle of $90^{\circ}$, and matrix removal is less as compared with other impingement angles (Figures 8(a)$8(\mathrm{f}))$. As bamboo fiber reinforced epoxy composites are not as ductile as metals, the surface shows mixed-damage processes. As discussed earlier for ductile materials, repeated impacts lead to plastic deformation processes and heavily strained regions on the composite surface. In the case of brittle materials on other hand, the propagation of cracks grows towards the surface and their intersection to form a wear particle separated from the surface leads to additional mass loss of the composite.
3.4. Effect of Impact Velocity on Erosion Rate. The speed of erosive particle has a very strong effect on the wear process. If the speed is very low, then the stresses at impact are insufficient for plastic deformation to occur and wear proceeds by surface fatigue. When the speed increases, it is possible for the eroded material to deform plastically on particle impact. In this contest, effect of impact velocity of particle on erosion rate is studied, and the results are represented in Figure 9. It is evident from the figure that at low impact velocity from $35 \mathrm{~m} / \mathrm{sec}$ to $45 \mathrm{~m} / \mathrm{sec}$, there is not much variation in erosion rate (denoted as phase-1).

However, with the further increase in impact velocity, the erosion rate is significantly increasing, that is, up to $55 \mathrm{~m} / \mathrm{sec}$ (denoted as phase 2). This may be due to the fact that at higher impact velocity, the erosion is occurring due to plastic deformation and more amount of material is removed. On further increase in impact velocity, all the composites show 


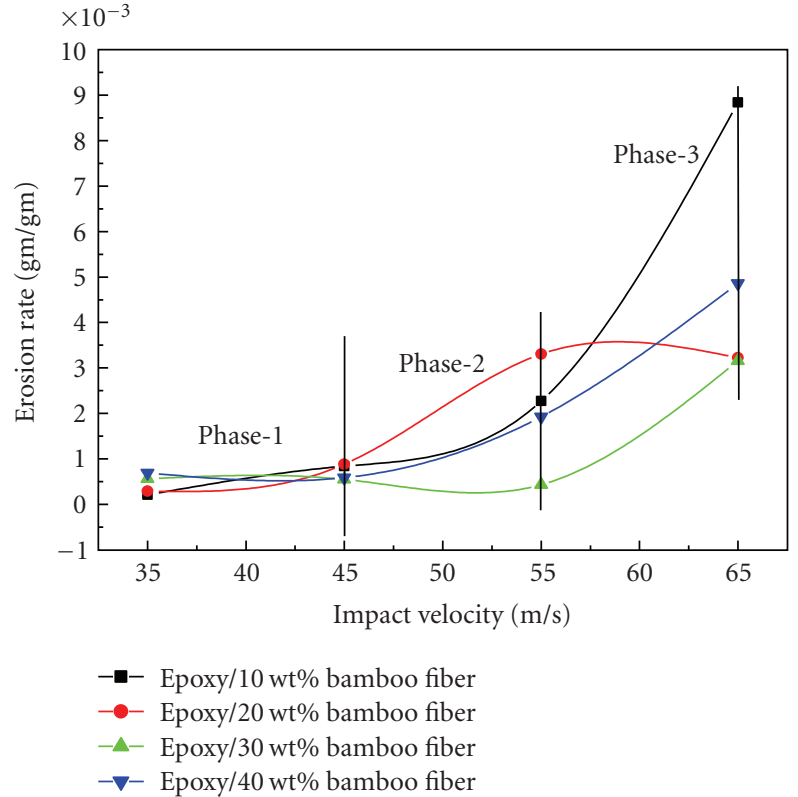

FIGURE 9: Effect of impact velocity on the erosion wear rate of the composites.

gradual increase in erosion rate except $20 \mathrm{wt} \%$ bamboofiber-reinforced epoxy composites which shows quite reverse in trend as shown in Figure 9.

3.5. Surface Morphology. Figure 10 shows the SEM observations of the eroded surfaces as a function of impact velocity under constant operating conditions such as impingement angle $60^{\circ}$, stand-off distance $65 \mathrm{~mm}$, and erodent size $250 \mu \mathrm{m}$ for bamboo-epoxy composites, respectively. Figures 10(a) and 10 (b) show the micrograph of the same composite surface (10 wt \%) eroded at an impingement angle of $60^{\circ}$ and an impact velocity of $35 \mathrm{~m} / \mathrm{sec}$. The matrix covering the fiber seems to be chipped off, and the crater thus formed shows the fiber body which is almost intact. The signs of plastic deformation of the matrix material, and when, impacting at such a low impact velocity $(35 \mathrm{~m} / \mathrm{sec})$, the hard erodent particles penetrate the surface and cause material removal mostly. Figures 10(c) and 10(d) show fragmentation of the fibers as a result of cracks, and multiple fractures are also distinctly shown in micrograph under similar impingement angle $\left(60^{\circ}\right)$. After the local removal of matrix, the arrays of fibers are normally exposed to erosive environment. At low impact velocity $(45 \mathrm{~m} / \mathrm{sec})$ and impingement angle $\left(60^{\circ}\right)$, the damage to the surface is minimal as seen in Figures 10(e) and 10 (f). Subsequently the material removal becomes faster. The wear trace is distinctly visible, and there is protrusion of fibers beneath the matrix layer as seen in Figure 10(g). The broken fiber, seen in Figure 10(h) are mixed with the matrix microflake debris, and the damage of the composite is characterized by separation and detachment of this debris at an impingement angle of $60^{\circ}$. Regions were formed due to simultaneous generation of cracks characteristic of brittle materials. The extent of plastic indentation, however, decreased as the angle of impingement decreased as seen in other micrographs (Figures 10(i) and 10(j)).

3.6. Effect of Erodent Size on Erosion Rate. The erosion rate of bamboo-fiber-reinforced epoxy composites have been studied by varying erodent size from $125 \mu \mathrm{m}$ to $350 \mu \mathrm{m}$ at constant impact velocity $(45 \mathrm{~m} / \mathrm{sec})$, impingement angle $\left(60^{\circ}\right)$, and stand-off distance $(65 \mathrm{~mm})$ as shown in Figure 11 . From Figure 11, it is observed, that with the increase in erodent size from $125 \mu \mathrm{m}-175 \mu \mathrm{m}$, the erosion rate almost remained constant.

In contrast, the erosion rate increased appreciably on further increasing the erodent size from $175 \mu \mathrm{m}$ to $275 \mu \mathrm{m}$, and on further increasing the erodent size from $275 \mu \mathrm{m}$ to $350 \mu \mathrm{m}$, the erosion rate starts decreasing. As reported by Biswas and Satapathy $[38,39]$ and Patnaik et al. [40], for glass fiber-reinforced polymer composites, with the increase in erodent size, the erosion rate increases gradually irrespective of fiber loading. It is also observed that the composite with $40 \mathrm{wt} \%$ of bamboo fiber loading shows most erosion resistant closely followed by the composite with $20 \mathrm{wt} \%$, $30 \mathrm{wt} \%$, and $10 \mathrm{wt} \%$ of bamboo fiber loading.

\section{Conclusions}

This mechanical and the erosion behaviour of bamboofiber-reinforced epoxy composites leads to the following conclusions.

(1) The composites which are suitable for applications in highly erosive environments can be prepared by reinforcement of bamboo fibers in epoxy resin. The erosion wear performance of these composites improves quite significantly by addition of bamboo fibers.

(2) It is evident from this study that the void content increases with increase in fiber loading and is maximum for composites with $30 \mathrm{wt} \%$ fiber loading. However, on further increase in fiber loading, the void content starts decreasing. As far as hardness is concerned for bamboo-epoxy composites, with increase in fiber loading, the hardness increases gradually from $24.5 \mathrm{Hv}$ to $37 \mathrm{Hv}$.

(3) The tensile strength shows maximum at $40 \mathrm{wt} \%$ fiber loading among other composites. The difference in the tensile strength depending on the kind of fiber can also be caused by other factors, such as the fiber length, and hydrophilicity as well as the difference in the chemical nature of the fiber.

(4) The flexural strength increased with the increase in fiber loading up to $20 \mathrm{wt} \%$. For instance, flexural strength of bamboo-epoxy composite is increased from $137.5 \mathrm{MPa}$ to $163.8 \mathrm{MPa}$, and then decreased from $163.8 \mathrm{MPa}$ to $140.9 \mathrm{MPa}$, that is, up to $30 \mathrm{wt} \%$ but, on further increase in fiber loading, the flexural strength increases from $140.9 \mathrm{MPa}$ to $173.8 \mathrm{MPa}$. However, as far as interlaminar shear strength and 


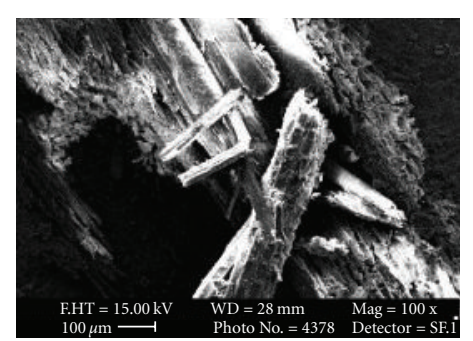

(a)

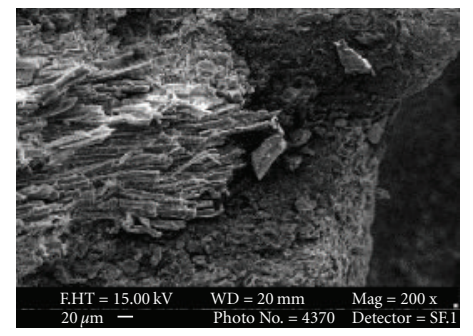

(d)

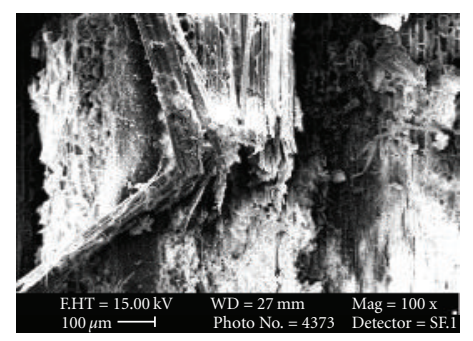

(g)

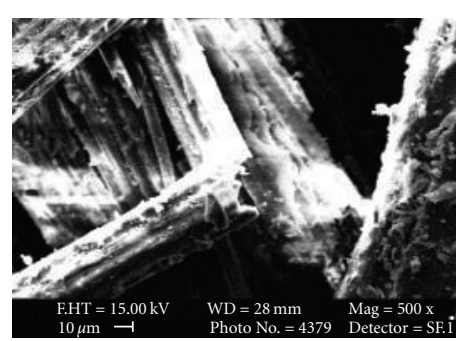

(b)

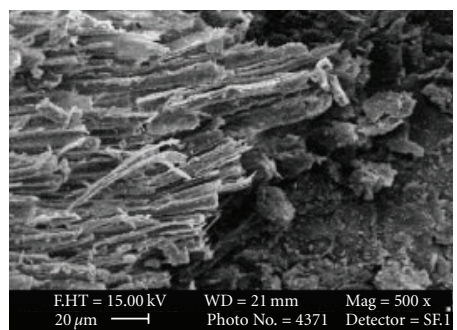

(e)

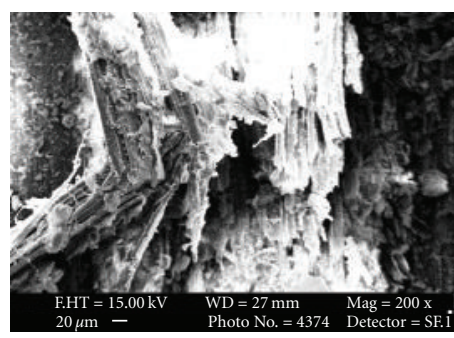

(h)

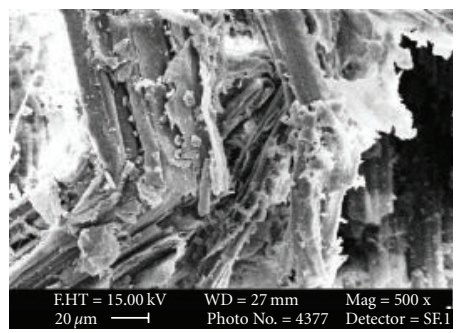

(j)

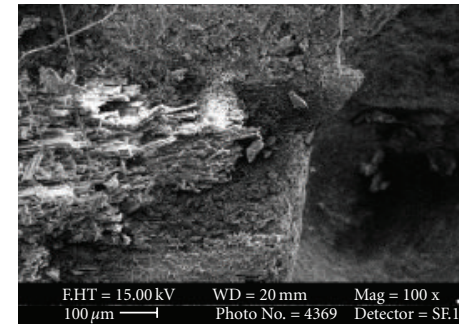

(c)

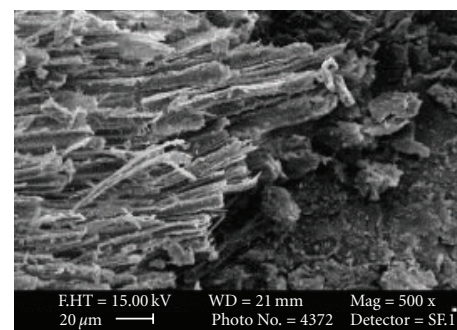

(f)

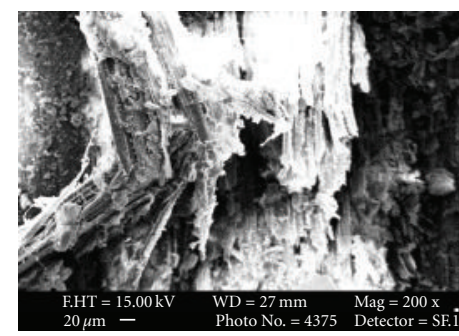

(i)

FIGURE 10: SEM observations of eroded samples with the variations of impact velocity.

tensile modulus are concerned, $20 \mathrm{wt} \%$ fiber loading show maximum strength and modulus.

(5) In this study, the impact strength increases linearly with increase in fiber loading from 0 to $20 \mathrm{wt} \%$, that is, from $\sim 0.639$ to $0.666 \mathrm{~J}$, and then decreases nominal amount of energy $(0.639 \mathrm{~J})$, but, on further increase in fiber loading, the impact strength increases gradually with the increase in impact strength $(0.866 \mathrm{~J})$.

(6) Study of influence of impingement angle on erosion rate of the composites filled with different weight percentage of fiber loading reveals their semibrittle nature with respect to erosion wear. The peak erosion rate is found to be occurring at $60^{\circ}$ to $75^{\circ}$ impingement angle for all the composite samples under various experimental conditions irrespective of fiber loading.

(7) For bamboo fiber composite, severe deterioration of both fiber and matrix, microploughing in the matrix, transverse shearing, stripping, and fibrillation of fiber are identified, and composite debonding, pulling, and fiber fracture are the characteristic features of damage in bamboo fiber.

(8) Possible use of these composites in components such as pipes carrying coal dust, helicopter fan blades, desert roof structures, industrial fans, and low cost housing is recommended. In future, this study can be extended to new hybrid composites using potential 


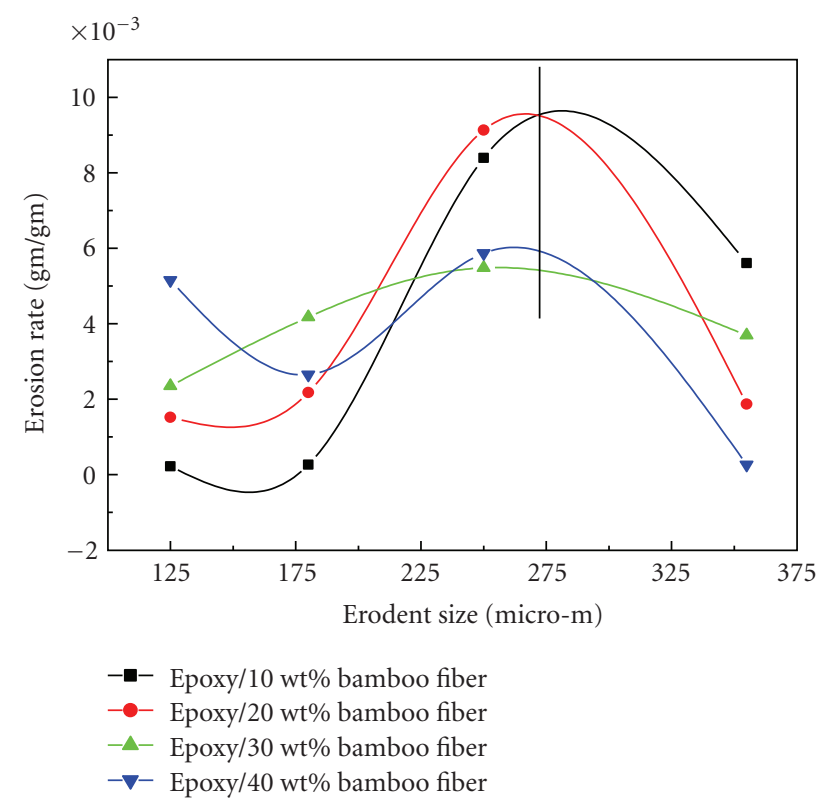

Figure 11: Effect of erodent size on the erosion wear rate of the composites.

fillers, and the resulting experimental findings can be similarly analyzed.

(9) The applications of natural fibers as reinforcement for polymer composites are reduced by the hydrophilic nature of natural fibers. The poor moisture resistance and poor wettability of natural fibers with hydrophobic polymers affect the interaction bonding between fiber and matrix interface. Therefore, chemical treatment of the fiber may improve the mechanical properties and wear resistance of the bamboo fiber-epoxy composites significantly as compared with the untreated bamboo-fiber-reinforced composites. However, fabrication techniques have also depended on the improvement of physical, mechanical, and wear resistance. It is recommended that the use of injection moulding technique to fabricate composite samples for testing is more precise and it reduced much of human factor's error, such as machining the composite to testing specimen which has critical dimensions.

\section{References}

[1] S. Öztürk, "Effect of fiber loading on the mechanical properties of kenaf and fiberfrax fiber-reinforced phenolformaldehyde composites," Journal of Composite Materials, vol. 44, no. 19, pp. 2265-2288, 2010.

[2] S. Biswas, S. Kindo, and A. Patnaik, "Effect of fiber length on mechanical behavior of coir fiber reinforced epoxy composites," Fibers and Polymers, vol. 12, no. 1, pp. 73-78, 2011.

[3] J. W. Kim, J. J. Lee, and D. G. Lee, "Effect of fiber orientation on the tensile strength in fiber-reinforced polymeric composite materials," Key Engineering Materials, vol. 297-300, pp. 2897 2902, 2005.
[4] E. S. AL-Hassani and S. R. Areef, "The effect of fiber orientation on creep behavior and flextural strength in epoxy composites," Engineering \& Technology Journal, vol. 28, no. 7, pp. 1281-1289, 2010.

[5] H. M. Clark, "Particle velocity and size effects in laboratory slurry erosion measurements OR... do you know what your particles are doing?" Tribology International, vol. 35, no. 10, pp. 617-624, 2002.

[6] A. P. Harsha and A. A. Thakre, "Investigation on solid particle erosion behaviour of polyetherimide and its composites," Wear, vol. 262, no. 7-8, pp. 807-818, 2007.

[7] N. M. Barkoula and J. Karger-Kocsis, "Effects of fibre content and relative fibre-orientation on the solid particle erosion of GF/PP composites," Wear, vol. 252, no. 1-2, pp. 80-87, 2002.

[8] V. K. Srivastava, "Effects of wheat starch on erosive wear of E-glass fibre reinforced epoxy resin composite materials," Materials Science and Engineering A, vol. 435-436, pp. 282287, 2006.

[9] R. Zhou, D. H. Lu, Y. H. Jiang, and Q. N. Li, "Mechanical properties and erosion wear resistance of polyurethane matrix composites," Wear, vol. 259, no. 1-6, pp. 676-683, 2005.

[10] R. Rattan and J. Bijwe, "Influence of impingement angle on solid particle erosion of carbon fabric reinforced polyetherimide composite," Wear, vol. 262, no. 5-6, pp. 568-574, 2007.

[11] J. Bijwe and R. Rattan, "Influence of weave of carbon fabric in polyetherimide composites in various wear situations," Wear, vol. 263, no. 7-12, pp. 984-991, 2007.

[12] V. K. Srivastava and A. G. Pawar, "Solid particle erosion of glass fibre reinforced flyash filled epoxy resin composites," Composites Science and Technology, vol. 66, no. 15, pp. 30213028, 2006.

[13] U. S. Tewari, A. P. Harsha, A. M. Häger, and K. Friedrich, "Solid particle erosion of unidirectional carbon fibre reinforced polyetheretherketone composites," Wear, vol. 252, no. 11-12, pp. 992-1000, 2002.

[14] U. S. Tewari, A. P. Harsha, A. M. Häger, and K. Friedrich, "Solid particle erosion of carbon fibre- and glass fibre-epoxy composites," Composites Science and Technology, vol. 63, no. 3-4, pp. 549-557, 2003.

[15] H. Zhang, Z. Zhang, and K. Friedrich, "Effect of fiber length on the wear resistance of short carbon fiber reinforced epoxy composites," Composites Science and Technology, vol. 67, no. 2, pp. 222-230, 2007.

[16] A. Patnaik, A. Satapathy, M. Dwivedy, and S. Biswas, "Wear behavior of plant fiber (Pine-Bark) and cement kiln dustreinforced polyester composites using Taguchi experimental model," Journal of Composite Materials, vol. 44, no. 5, pp. 559574, 2010.

[17] B. D. Agarwal and L. J. Broutman, Analysis and Performance of Fiber Composites, John Wiley and Sons, New York, NY, USA, 2nd edition, 1990.

[18] A. W. Ruff and L. K. Ives, "Measurement of solid particle velocity in erosive wear," Wear, vol. 35, no. 1, pp. 195-199, 1975.

[19] J. A. E. Månson, M. D. Wakeman, and N. Bernet, "Composite processing and manufacturing-an overview," in Comprehensive Composite Materials, A. Kelly and C. Zweben, Eds., vol. 2, chapter 2, pp. 577-607, Elsevier, Amsterdam, The Netherlands, 2000.

[20] H. Lilholt and A. B. Bjerre, "Composites based on jute-fibres and polypropylene matrix, their fabrication and characterization," in Proceedings of the 18th Risø International Symposium on Materials Science, Polymeric Composites - Expanding the 
Limits, pp. 411-423, Risø National Laboratory, Roskilde, Denmark, 1997.

[21] B. Madsen, Properties of plant fibre yarn polymer compositesan experimental study, Ph.D. thesis, Technical University of Denmark, Department of Civil Engineering, 2004.

[22] A. Thygesen, Properties of hemp fibre polymer composites-an optimisation of fibre properties using novel defibration methods and detailed fibre characterization, Ph.D. thesis, The Royal Veterinary and Agricultural University, Danish Centre for Forest, Landscape and Planning, 2005.

[23] B. Madsen and H. Lilholt, "Compaction of plant fibre assemblies," in Proceedings of the 23rd Risø International Symposium on Materials Science, Sustainable Natural and Polymeric Composites-Science and Technology, pp. 239-250, Risø National Laboratory, Roskilde, Denmark, 2002.

[24] K. Oksman, "Mechanical properties of natural fibre mat reinforced thermoplastic," Applied Composite Materials, vol. 7, no. 5-6, pp. 403-414, 2000.

[25] T. H. Ferrigno, Handbook of Fillers and Reinforcements for Plastics, Van Nostrand Reinhold, New York, NY, USA, 1978.

[26] L. Y. Mwaikambo and E. T. N. Bisanda, "Performance of cotton-kapok fabric-polyester composites," Polymer Testing, vol. 18, no. 3, pp. 181-198, 1999.

[27] L. W. H. Leonard, K. J. Wong, K. O. Low, and B. F. Yousif, "Fracture behaviour of glass fibre-reinforced polyester composite," Proceedings of the Institution of Mechanical Engineers, Part L, vol. 223, no. 2, pp. 83-89, 2009.

[28] K. J. Wong, B. F. Yousif, K. O. Low, Y. Ng, and S. L. Tan, "Effects of fillers on the fracture behaviour of particulate polyester composites," Journal of Strain Analysis for Engineering Design, vol. 45, no. 1, pp. 67-78, 2010.

[29] H. Ismail, M. R. Edyham, and B. Wirjosentono, "Bamboo fibre filled natural rubber composites: the effects of filler loading and bonding agent," Polymer Testing, vol. 21, no. 2, pp. 139144, 2002.

[30] W. Yao and Z. Li, "Flexural behavior of bamboo-fiberreinforced mortar laminates," Cement and Concrete Research, vol. 33, no. 1, pp. 15-19, 2003.

[31] M. Bagueri, "The Three-points Bending Test," in Critical Review Proceedings of the 8th Japan-US Conference on Composite Materials, pp. 683-692, Technomic Publ., Baltimore, Md, USA, 1998.

[32] Q. Zhao, J. Tao, R. C. M. Yam, A. C. K. Mok, R. K. Y. Li, and C. Song, "Biodegradation behavior of polycaprolactone/rice husk ecocomposites in simulated soil medium," Polymer Degradation and Stability, vol. 93, no. 8, pp. 1571-1576, 2008.

[33] H. S. Yang, H. J. Kim, J. Son, H. J. Park, B. J. Lee, and T. S. Hwang, "Rice-husk flour filled polypropylene composites; mechanical and morphological study," Composite Structures, vol. 63, no. 3-4, pp. 305-312, 2004.

[34] M. S. Huda, L. T. Drzal, A. K. Mohanty, and M. Misra, "Effect of fiber surface-treatments on the properties of laminated biocomposites from poly(lactic acid) (PLA) and kenaf fibers," Composites Science and Technology, vol. 68, no. 2, pp. 424-432, 2008.

[35] H. G. B. Premalal, H. Ismail, and A. Baharin, "Comparison of the mechanical properties of rice husk powder filled polypropylene composites with talc filled polypropylene composites," Polymer Testing, vol. 21, no. 7, pp. 833-839, 2002.

[36] J. C. Arnold and I. M. Hutchings, "Erosive wear of rubber by solid particles at normal incidence," Wear, vol. 161, no. 1-2, pp. 213-221, 1993.
[37] J. C. Arnold and I. M. Hutchings, "Model for the erosive wear of rubber at oblique impact angles," Journal of Physics D, vol. 25, no. 1A, pp. A222-A229, 1992.

[38] S. Biswas and A. Satapathy, "Erosion wear analysis of $\mathrm{SiC}$ filled glass-epoxy composites using Taguchi technique," International Polymer Processing, vol. 25, no. 1, pp. 23-33, 2009.

[39] S. Biswas and A. Satapathy, "An assessment of erosion wear response of $\mathrm{SiC}$ filled epoxy composites reinforced with glass and bamboo fibers," International Polymer Processing, vol. 25, no. 3, pp. 205-222, 2010.

[40] A. Patnaik, A. Satapathy, S. S. Mahapatra, and R. R. Dash, "Erosive wear assesment of glass reinforced polyester-flyash composites using taguchi method," International Polymer Processing, vol. 23, no. 2, pp. 192-199, 2008. 

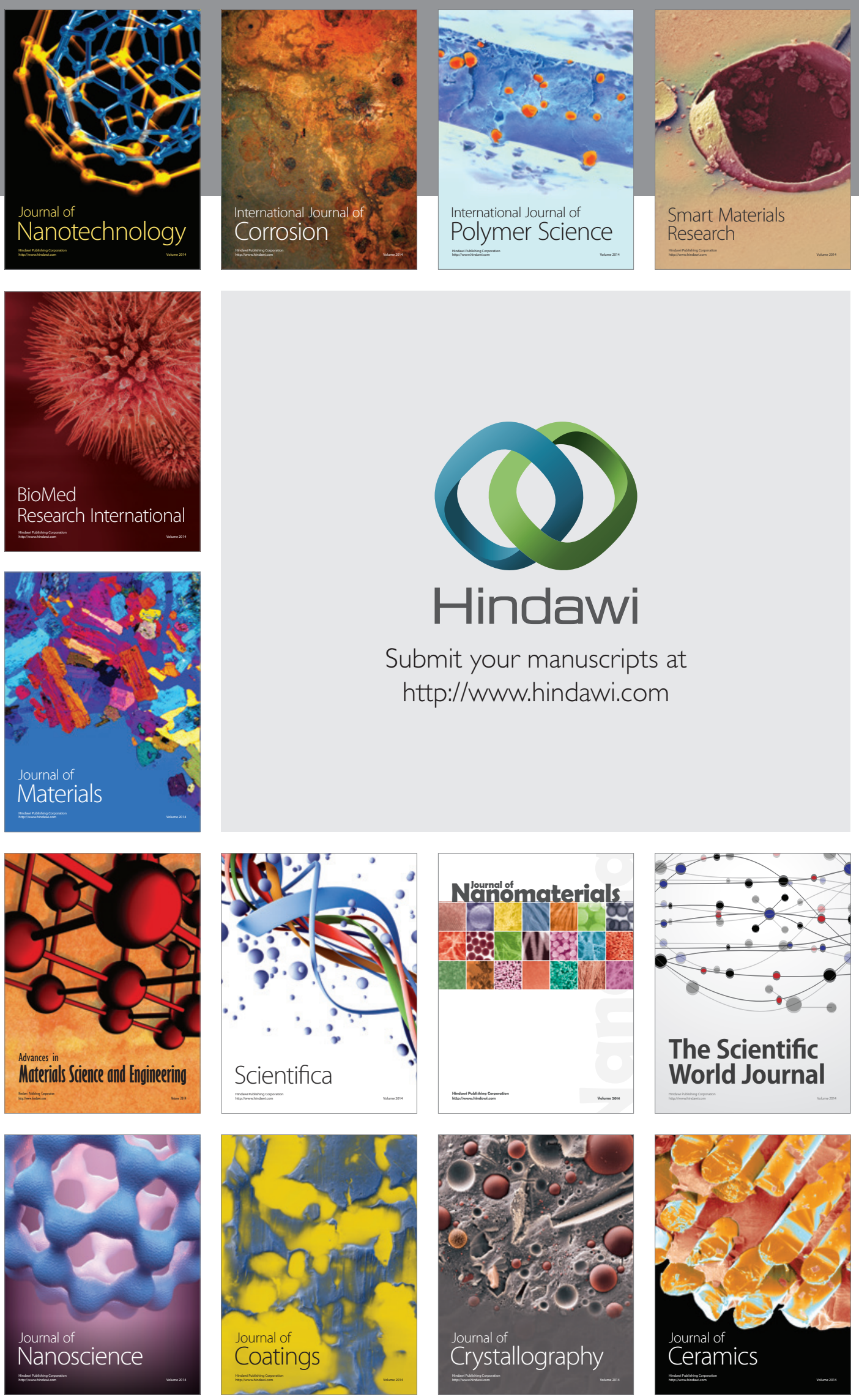

The Scientific World Journal

Submit your manuscripts at

http://www.hindawi.com

\section{World Journal}

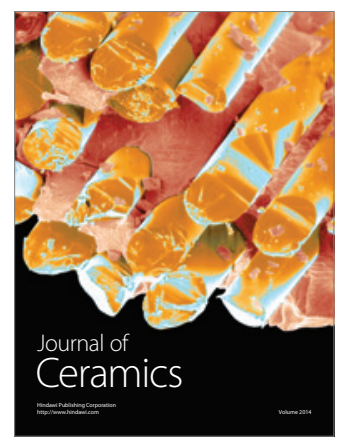

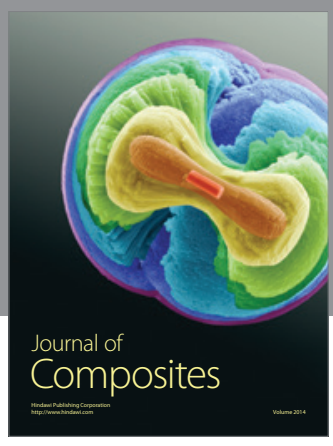
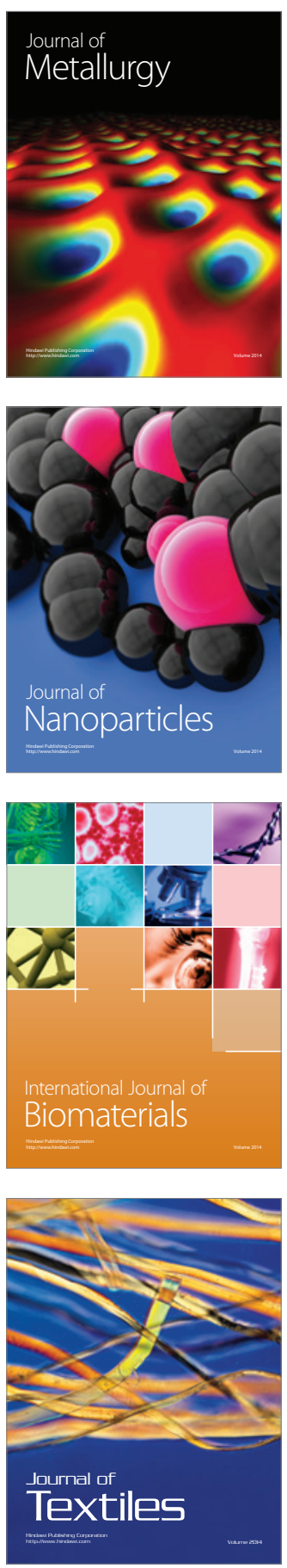